УДК 51(09)

\title{
Колективна стаття
}

Дніпровський національний університет імені Олеся Гончара

\section{Лілія Георгївна Бойцун (пам'яті математика і яскравої особистості)}

Анотація. Статтю присвячено талановитому математику, кандидату фізикоматематичних наук Бойцун Лілії Георгіївні. У статті висвітлено їі життєвий шлях і трудовий та науковий доробок.

Ключові слова: тригонометричний інтеграл Фур'є, метод Вороного

Abstract. The article is devoted to the talented mathematician, candidate of physical and mathematical sciences Boitsun Lilia Georgiivna. The article describes her life and career, scientific activity.

Key words: trigonometric Fourier integral, Voronoi method

MSC2020: PRI 01A70 SEC 40A 10

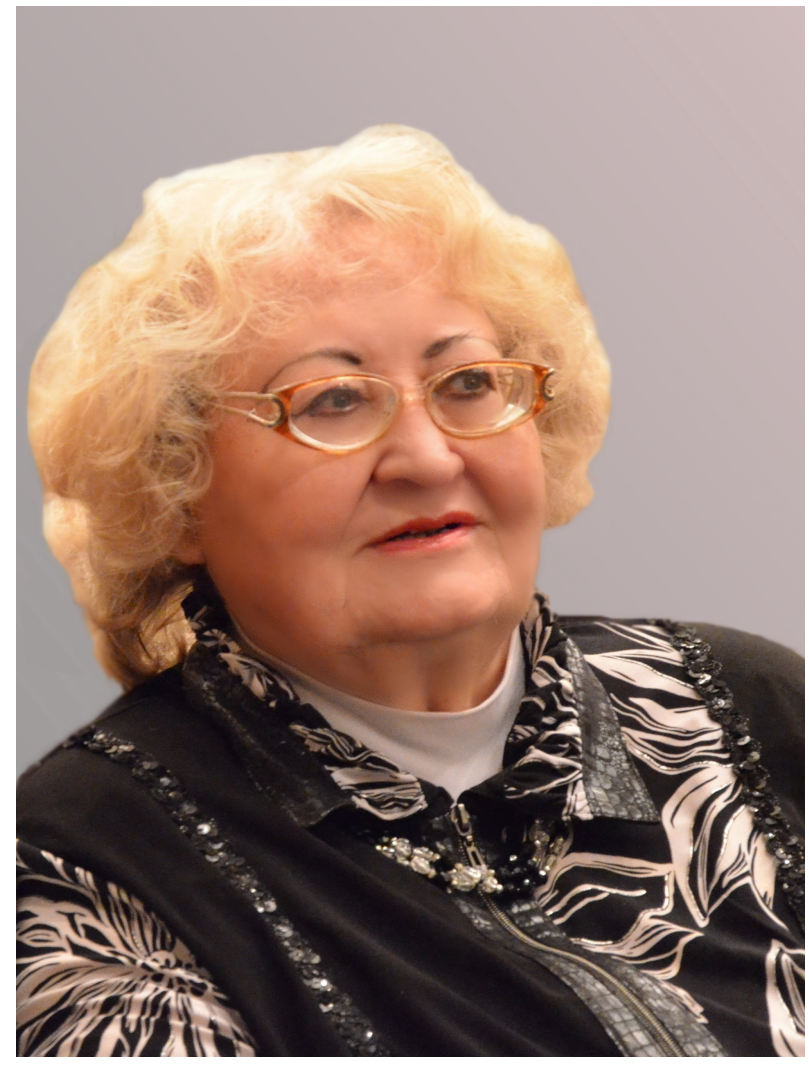


12 березня 2021 року пішла з життя кандидат фізико-математичних наук, доцент Л. Г. Бойцун. Її життєвий шлях був тісно пов'язаний із математикою та механіко-математичним факультетом Дніпровського національного університету імені Олеся Гончара.

Лілія Георгї̈вна Бойцун народилася 16 січня 1939 року в місті Дніпропетровськ (нині Дніпро) у багатодітній родині мастера-ремонтника доменних печей і домогосподарки. Дитинство забрала війна, а в повоєнні роки родина жила бідно і часто голодувала. Лілія Георгіївна навчалась у дніпропетровській школі № 59, де вчителька математики помітила талановиту й обдаровану дівчинку і порадила їй вступити до Дніпропетровського державного університету (нині Дніпровський національний університет імені Олеся Гончара) на спеціальність "математика". Так у 1957 році, успішно склавши іспити, Л. Г. Бойцун стала студенткою механікоматематичного факультету. У 1961 році одержала диплом з відзнакою і вступила до аспірантури за кафедрою математичного аналізу. Ї̈̈ науковим керівником був кандидат фізико-математичних наук Ілля Ісаакович Огієвецький, який дуже схвалював Лілію за любов до праці і вважав її взірцем для інших аспірантів.

У 1966 році Л. Г. Бойцун захистила кандидатську дисертацію на тему "Підсумовування інтегралів Фур'є методом Г. Ф. Вороного", а в 1967 році отримала науковий ступінь кандидата фізико-математичних наук.

Свою трудову діяльність вона розпочала в жовтні 1964 року асистентом кафедри математичного аналізу. Вже в грудні 1964 року її було переведено на посаду старшого викладача кафедри. 31968 року і до закінчення трудової діяльності (квітень 2014 року) Л. Г. Бойцун працювала доцентом кафедри математичного аналізу (з 2010 року - математичного аналізу і теорії функцій). Вона читала низку курсів (математичний аналіз, диференціальні рівняння, вищу математику, теорію ймовірностей і математичну статистику, методи математичної фізики, теорію функцій комплексної змінної) для студентів різних факультетів і спеціальний курс з теорії підсумовування рядів та інтегралів для студентів кафедри математичного аналізу.

Лілія Георгіӥвна багато років здійснювала керівництво педагогічною практикою студентів спеціальності "Математика". Була членом вченої ради механікоматематичного факультету, членом спеціалізованої вченої ради із захисту кандидатських дисертацій зі спеціальності 01.01.01 - математичний аналіз. Вона входила до складу редколегії наукового журналу "Дослідження із сучасних проблем підсумовування і наближення функцій та їх застосування".

Л. Г. Бойцун протягом багатьох років була заступником завідувача кафедри (М. І. Алхімова, К. М. Слєпєнчука), з 1977 по 2013 роки була головою профбюро механіко-математичного факультету і членом профкому університету.

Лілія Георгї̈вна завжди жила за принципом "Університет не тільки навчає, але й виховує". Робота зі студентами завжди була для неї пріоритетом. Студенти дуже її любили і поважали.

Л. Г. Бойцун брала участь у багатьох міжнародних конференціях, з'їздах, симпозіумах, де виступала з доповідями. Вона опублікувала понад 120 наукових робіт, 
у тому числі низку статей англійською мовою.

Лілія Георгіӥвна першою застосувала метод Вороного до підсумовування тригонометричних інтегралів Фур'є і взяла активну участь у присвоєнні використовуваному методу імені Вороного. Звернемося до історії. У 1901 році відомий український математик Г. Ф. Вороний уперше застосував власний новий функціональний метод підсумовування рядів. Ним була опублікована невелика стаття в “Дневнике VI съезда русских естествоиспытателей и врачей". Проте математична спільнота не приділила належної уваги цьому відкриттю. Через вісімнадцять років датський учений Н. Е. Ньорлунд увів цей самий метод підсумовування, який більш ніж половину сторіччя був відомий як метод Ньорлунда. Наразі ім'я Г. Ф. Вороного повернули Україні і світу, а метод підсумовування розбіжних рядів тепер називають методом Ньорлунда-Вороного. Великий внесок у справу повернення імені Вороного зробила кафедра математичного аналізу Дніпропетровського державного університету. Зокрема, немалу роботу по відновленню істини провела кандидат фізико-математичних наук Л. Г. Бойцун.

Наукові дослідження Л. Г. Бойцун проводила в області підсумовування тригонометричних інтегралів Фур'є методом Вороного і його узагальненнями. Опишемо основні результати. Для цього спочатку введемо необхідні поняття.

Нехай задано функцію $f(u)$, яка є інтегровною на кожному скінченному проміжку $[0, A], A>0$, і $S(u)=\int_{0}^{u} f(t) d t$. Крім того, нехай $p(t)-$ функція, що є інтегровною на кожному скінченному інтервалі і $P(y)=\int_{0}^{y} p(t) d t \neq 0$.

Говорять, що $\int_{0}^{\infty} f(t) d t$ підсумовується методом Вороного $((W, p(y))$-методом) до $I$, якщо

$$
\lim _{y \rightarrow \infty} \tau(y)=\lim _{y \rightarrow \infty} \frac{1}{P(y)} \int_{0}^{y} p(y-u) S(u) d u=I .
$$

Якщо $\int_{0}^{\infty}\left|\tau^{\prime}(y)\right| d y<\infty$, то говорять, що інтеграл $\int_{0}^{\infty} f(t) d t$ абсолютно підсумовується методом Вороного, або $|W, p(y)|$-сумовний.

У випадку. коли $p(t)=\alpha t^{\alpha-1}, \alpha>0$, метод Вороного перетворюється на добре відомий метод Чезаро $((C, \alpha)$-метод, $\alpha>0)$. Якщо $p(t)=\frac{1}{1+t}$, отримуємо метод гармонічних середніх.

Говорять, що $\int_{0}^{\infty} f(t) d t$ підсумовується добутком методу Чезаро першого порядку і методу Вороного $((C, 1) \cdot(W, p(y))$-сумовний) до $I$, якщо

$$
\lim _{y \rightarrow \infty} \sigma(y)=\lim _{y \rightarrow \infty} \frac{1}{y} \int_{0}^{y} \tau(\lambda) d \lambda=I,
$$


і абсолютно сумовний $(C, 1) \cdot(W, p(y))$-методом (або $|(C, 1) \cdot(W, p(y))|$-сумовний $)$, якщо $\int_{0}^{\infty}\left|\sigma^{\prime}(y)\right| d y<\infty$.

$\int_{0}^{\infty} f(t) d t$ сумовний $(W, p(y)) \cdot(C, 1)$-методом до $I$, якщо

$$
\lim _{y \rightarrow \infty} \omega(y)=\lim _{y \rightarrow \infty} \frac{1}{P(y)} \int_{0}^{y} p(y-u) \tau_{1}(u) d u=I
$$

де

$$
\tau_{1}(y)=\int_{0}^{y}\left(1-\frac{u}{\lambda}\right) f(\lambda) d \lambda
$$

і абсолютно сумовний цим методом або, коротко $|(W, p(y)) \cdot(C, 1)|$-сумовний, якщо $\int_{0}^{\infty}\left|\omega^{\prime}(y)\right| d y<\infty$

Нехай функція $f(t) \in L(-\infty, \infty)$. Будемо розглядати її інтеграл Фур'е

$$
\frac{1}{\pi} \int_{0}^{\infty} d u \int_{-\infty}^{+\infty} f(t) \cos u(t-x) d t
$$

спряжений інтеграл Фур'є

$$
\frac{1}{\pi} \int_{0}^{\infty} d u \int_{-\infty}^{+\infty} f(t) \sin u(t-x) d t
$$

продиференційований інтеграл Фур'є

$$
\frac{1}{\pi} \int_{0}^{\infty} u d u \int_{-\infty}^{+\infty} f(t) \sin u(t-x) d t
$$

спряжений продиференційований інтеграл Фур'є

$$
\frac{1}{\pi} \int_{0}^{\infty} u d u \int_{-\infty}^{+\infty} f(t) \cos u(t-x) d t
$$

Дослідження Л. Г. Бойцун щодо підсумовування тригонометричних інтегралів Фур'є можна розділити на декілька напрямів. 
1. Звичайна сумовність інтегралів (1), (2), (3), (4). Основним результатом, отриманим в цьому напрямку, є така теорема (див. [1]).

Теорема 1. Нехай $p(t)$ - додатна, монотонно зростаюча функціл, така, що $P(y) \rightarrow \infty, y \rightarrow \infty$. Якщо

$$
\int_{0}^{t} \frac{|f(x+u)+f(x-u)-2 f(x)|}{2} d u=o\left(\frac{p\left(\frac{1}{t}\right)}{P\left(\frac{1}{t}\right)}\right), \quad t \rightarrow+0,
$$

то інтеграл (1) підсумовуеться $(W, p(y))$-методом до $f(x)$ в точиі $t=x$.

Аналогічні результати були одержані для інтегралів (2), (3), (4).

2. Абсолютна сумовність методом Вороного тригонометричних інтегралів Фур'є. Результатом досліджень Лілії Георгї̈вни в цьому напрямку стала така важлива теорема (див. [2]).

Теорема 2. Нехай $p(t)$ - додатна, монотонна й диференційовна функціл, та$\kappa a, \varkappa_{\circ} P(y) \rightarrow \infty, y \rightarrow \infty$,

$$
\frac{y p(y)}{P(y)} \in B V(0,+\infty) ; \quad \frac{1}{P(y)} \int_{0}^{y} \frac{P(u)}{u} d u \in B V(0 ;+\infty) .
$$

Якщо

$$
\frac{f(x+t)+f(x-t)}{2} \in B V(0 ;+\infty),
$$

то інтеграл (1) функиї $f \in L(-\infty,+\infty)$ підсумовується $|W, p(y)|$-методом в точиi $t=x$.

Ці дослідження були продовжені індійськими вченими S. N. Lal i S. Ram y 1974 році і S. N. Lal i K. N. Singh у 1980 році. У них змінювались умови, яким підпорядкована точка підсумовування, але функція $p(y)$, що породжує метод підсумовування, мала сталий знак і була монотонною. У роботах Л. Г. Бойцун і Т. І. Рибнікової були отримані достатні умови абсолютної сумовності тригонометричних інтегралів для випадку, коли функція $p(y)$ не є знакосталою і монотонною.

3. Абсолютна сумовність інтегралів Фур'є добутком методів $(C, 1)$. $(W, p(y)) \mathbf{i}(W, p(y)) \cdot(C, 1)$. Перші дослідження в цьому напрямі було опубліковано у 1973 році (див. [3]).

Теорема 3. Якщо

$$
\frac{1}{t} \int_{0}^{t}(f(x+u)-f(x-u)) d u \in B V(0,+\infty)
$$


$i$

$$
P(y) \int_{0}^{\infty} \frac{d u}{u P(u)} \leq K,
$$

то інтеграл (1) функиіӥ $f \in L(-\infty,+\infty)$ абсолютно сумовний $(C, 1) \cdot(W, p(y))$ методом в точиі $t=x$.

Питання абсолютної сумовності $(W, p(y)) \cdot(C, 1)$-методом інтегралів $(1),(2),(3)$ були розглянуті в 1985-1987 роках.

\section{4. Про степінь наближення функції чезаровськими середніми її інтегра-} лу Фур'є. Важливим результатом в цьому напрямку є така теорема (див. [4]).

Теорема 4. Нехай $0<\alpha<1 i 0<\delta<\infty$. Якщо точка $x$ така, що $\varphi(t)=$ $f(x+t)+f(x-t)-2 f(x) \in L(0 ;+\infty) i$

$$
\int_{0}^{t}|d \varphi(u)| \leq K \hat{\psi}(t), \quad 0 \leq t \leq \delta,
$$

mо $\tau(y, x, \alpha)-f(x)=O\left(\hat{\psi}\left(\frac{1}{y}\right)\right)+O\left(\frac{1}{y^{\alpha}}\right)$, де $\hat{\psi}(t)-$ додатна зростаюча функиіл, така, що

$$
\int_{1 / y}^{\delta} \frac{\hat{\psi}(t)}{t^{2}} d t=O\left(y \hat{\psi}\left(\frac{1}{y}\right)\right), \quad y \rightarrow+\infty
$$

a $\tau(y, x, \alpha)-(C, \alpha)$-середні інтегралу (1).

5. Сумовність тригонометричних інтегралів Фур'є методом $\left(W, p^{\alpha}(y)\right)$. На відміну від методу $(W, p(y))$ в $\left(W, p^{\alpha}(y)\right)$-методі функція, яка його породжує, визначається в такий спосіб:

$$
\begin{gathered}
p^{\alpha}(y)=\frac{y^{\alpha-1}}{\Gamma(\alpha+1)} \int_{0}^{y}\left(1-\frac{t}{y}\right)^{\alpha-1} p(t) d t, \quad \alpha>-1, \\
P^{\alpha}(y)=\int_{0}^{y} p^{\alpha}(t) d t .
\end{gathered}
$$

Наведемо одну із теорем для інтеграла (1) (див. [5]). 
Теорема 5. Інтеграл (1) функиї $f(t) \in L(-\infty, \infty)$ підсумовуєтъся $\left(W, p^{\alpha}(y)\right)$ методом до $f(x)$ в будъ-якій точиі, де

$$
\int_{0}^{t}|f(x+u)+f(x-u)-2 f(x)| d u=o\left(\frac{p^{\alpha}\left(\frac{1}{t}\right)}{P^{\alpha}\left(\frac{1}{t}\right)}\right), \quad t \rightarrow+\infty .
$$

Tyт $p^{\alpha}(y)$ - невід'ємна неперервно диференційовна функціл, така, що $P^{\alpha}(y) \rightarrow$ $+\infty, y \rightarrow+\infty$.

Ці результати були опубліковані Л. Г. Бойцун у 2015 році, коли вона вже була на заслуженому відпочинку.

Механіко-математичний факультет ДНУ знає Лілію Георгіївну не лише як ученого і викладача, але і як творчу особистість. Вона була режисером, сценаристом і учасником багатьох свят, вечорів і капусників ММФ і Університету. Протягом 27 років вона брала участь у змаганнях KBK і була першим капітаном команди викладачів ДДУ (наразі ДНУ).

Лілія Георгіївна є автором багатьох поздоровлень, гумористичних і філософських віршів і творів, видала книгу "Приходите, споем!", присвячену народній хоровій капелі "Просвіта", членом якої вона була протягом 40 років. Підготувала до видання книгу про свята "Большого мехмата", під назвою "Страницами Дней мехмата", але, на жаль, не встигла її видати. Проте інші учасники цих заходів, які тепер живуть у різних куточках світу, вже завершують підготовку книги до видання. Лілія Георгіївна не переставала займатися самовдосконаленням, навіть коли вийшла на пенсію. Так, вона оволоділа роботою з комп'ютером і власноруч набирала всі материали для своїх книг.

За плідну роботу на користь факультету й університету Л. Г. Бойцун була нагороджена медалями "За трудову відзнаку" (1986), "Ветеран праці" (1986), нагрудним знаком "За визначні успіхи в роботі” (1989), почесною медаллю "За вірну службу ДНУ" (2008), "Почесною грамотою Міністерства освіти і науки України" (2009). Вона однією з перших в ДНУ одержала звання “Заслужений викладач Дніпропетровського університету" (1998).

Лілія Георгіївна завжди говорила, що не уявляє свого життя без рідного мехмату, як і мехмат неможливо уявити без Лілії Георгї̈вни. I факультет, і всі ті, кому пощастило зустрічатися та працювати з нею, не зможуть забути цю світлу й унікальну людину.

Світла пам’ять Лілії Георгіївні!

В. Ф. Бабенко, Р. О. Біліченко, М. Б. Вакарчук, О. В. Коваленко, С. В. Конарева, В. О. Кофанов, Т. Ю. Лескевич, В. П. Моторний, Н. В. Парфінович, А. М. Пасько, О. В. Поляков, О. О. Руденко, Т. І. Рибнікова, Д. С. Скороходов, М. Є. Ткаченко, В. М. Трактинська 


\section{Бібліографічні посилання}

1. Бойцун Л. Г.: Некоторые вопросы из теории тригонометрических интегралов Фурье. Сборник трудов механико-математического факультета по заказам промышленности Днепропетровска. ДГУ (1971), 234-242.

2. Бойцун Л. Г.: Об абсолютной суммируемости интегралов Фурье методом Г. Ф. Вороного. Труды I Республиканской научной конференции молодых исследователей. АН УССР Институт математики, Киев (1965), 60-67.

3. Бойчун Л. Г., Рыбникова Т. И.: Абсолютная $(C, 1) \cdot(B, p(y))$-суммируемость интеграла Фурье. Исследования по современным проблемам суммирования и приближения функций и их приложения. Днепропетровск: ДГУ (1973), 91-97.

4. Бойцун Л. Г., Рыбникова Т. И.: О степени приближения функций чезаровскими средними ее интеграла Фурье. Исследования по современным проблемам суммирования и приближения функций и их приложения. Днепропетровск: ДГУ (1973), 16-23.

5. Бойцун Л. Г., Рыбникова Т. И.: $\left(W, p^{\alpha}(y)\right)$-суммирование тригонометрических интегралов Фурье. Вісник Дніпропетровського університету. Серія Математика. 20 (2015), 12-18. doi:10.15421/241502

Received: 25.05.2021. Accepted: 30.06.2021 